\title{
Adjustment of Daily Activities: the Influence of Smartphone Adoption on the Travel Pattern of Mobile Professionals in the Greater Jakarta Area
}

\author{
Gloriani Novita Christin ${ }^{1}$, Ofyar Z. Tamin ${ }^{2}$, Idwan $\operatorname{Santoso}^{2} \&$ Miming Miharja ${ }^{1}$ \\ ${ }^{1}$ School of Architecture, Planning and Policy Development, \\ Institut Teknologi Bandung, Jalan Ganesha 10, Bandung 40132, Indonesia \\ ${ }^{2}$ Faculty of Civil and Environmental Engineering, Institut Teknologi Bandung \\ Jalan Ganesha 10, Bandung 40132, Indonesia \\ Email: glorinovi@yahoo.com
}

\begin{abstract}
The swift augmentation in the adoption of smartphones, the gadget that resulted from the convergence of Information and Communication Technology (ICT), potentially transforms people's life in myriad dimensions. One potential change induced by smartphones, is how people restructure their daily agenda and consecutively influence their travel pattern. To understand it, this study theoretically reviews mobile professional work, smartphone adoption, and how people conduct their mobile interaction, planning and execution of daily activities. Mobile professionals, the cohort of professionals that spend more than $20 \%$ of their total working time moving around out of their work environment; they are important beneficiaries of smartphones and have been chosen as the target of this study. Empirical results of mobile professionals' experiences in the Greater Jakarta Area are presented at this juncture. Furthermore, their adjustment of activities as a dynamic response to receiving extensive information via smartphones is also analysed. The results indicate that there is a strong adjustment of daily activities by mobile professionals. Through those changes, the transformation of daily travel patterns related to the activity is also brought about by the use of this high-end ICT contrivance.
\end{abstract}

Keywords: activity adjustment; mobile professional; smartphone; travel pattern.

\section{Introduction}

Throughout the contemporary decades, our society has experienced rapid developments of Information and Communication Technologies (ICT). ICT plays an important role in human life and affects where and how we work, study, shop, eat, play, live and travel [1,2]. As people currently enjoy new freedoms in space and time that allow them to carry out activities and interact with others using their ICT device, the worldwide mobile phone adoption continues to show significant growth. ITU [3] estimated that by the end of 2014 there would be approximately 7 billion mobile subscriptions. As the result of the convergence of ICT, smartphones emerged as state-of-the-art type of mobile

Received April 18 $8^{\text {th }}, 2014$, Revised July $24^{\text {th }}, 2014$, Accepted for publication October $15^{\text {th }}, 2014$.

Copyright (C) 2014 Published by ITB Journal Publisher, ISSN: 2337-5779, DOI: 10.5614/j.eng.technol.sci.2014.46.4.4 
phone that integrated a number of technologies for computing capabilities and advanced internet connectivity [4].

The smartphone market itself started out in the business segment $[5,6]$, and the so-called mobile professionals are especially important beneficiaries here. A mobile professional is defined as an individual aged over 20, who is employed full time in a professional occupation, and spends 20 per cent or more of his or her total working time moving out from his or her work environment [6-8]. The nature of mobile professionals' work differs in many ways from desk work, as it has a greater degree of unpredictability and heterogeneity caused by contextual constraints [9]. The number of mobile professionals in the world will climb to over 1.3 billion by 2015, up from 1.0 billion in 2010 [10]. Perry, et al. [11] stated that mobile professionals need additional supportive information in order to diminish their contextual constraints. Here, smartphones will possibly fulfil these needs.

The matter of interaction between the developments of ICT in individual travel behaviour is often expressed in a function of substitution (ICT acts to reduce travel), complementarity (ICT generates transport), modification (ICT acts to change the time, mode or route of travel), and neutrality (ICT does not affect travel) $[1,12,13]$. In order to investigate this interaction, this study uses the 'activity based travel' concept, particularly activity adjustment as an intermediary interaction between ICT (especially smartphone) and transport. There have been some empirical studies on adjustment of schedules (for instance, Joh [14]) and some proposals for conceptualization (see [15]) but the effect on this from using a smartphone specifically has not been taken into account. Besides, research on mobile professionals in Indonesia is still intermittent, mobile professionals are an interesting topic to investigate, because their activity-travel pattern has a high variability and they spend more time in the urban transportation network than non-mobile workers do. On the other hand, smartphone adoption in Indonesia has reached 68 million and will continue to increase [16], where mobile professionals are the earliest adopters of smartphone technologies and use it intensively during their work; therefore, they could be the cohort who senses the impact of smartphone adoption on their daily activities the most. Thus, it is important to explore the impact of the smartphone on individuals' (i.e. mobile professionals) activity-travel pattern, and how this enables them to plan, interact and execute their activities dynamically. 


\section{Theoretical Background and Hypothesis}

\subsection{Adoption of Smartphone and Transformation of Daily Life}

Following the convergence of ICT, the motive for adopting a smartphone is more powerful and it makes mobile phone users quickly shift to smartphones [5]. Smartphones extend the users' ability to check into social media sites, send and receive email, bank transactions, instant messaging, browse the Internet, check the traffic, and more. Therefore, Ericson [17] reported that in 2013, 30 per cent of all mobile phone subscriptions are associated with smartphones.

ICT itself has the potential to transform everyday life: how to interact, privacy, social networking, economics, education, and urban transport [18]. Kopomaa [19] and Townsend [20] found that that the use of the mobile phone is influencing people's life and social relationships in significant ways, and gives the possibility of conducting activities and interaction in novel ways, which results in an increasing spatial and temporal flexibility [21]. Hägerstrand [22] proposed three types of space-time constraints which determine individual space-time behaviour; i.e. (1) capability constraints; (2) coupling constraints; and (3) authority constraints. Dijst [23] asserted that the increasing use of ICT could alleviate some capability constraint and coupling constraint through its flexibility. The smartphone as the product of ICT potentially transforms daily life.

\subsection{The Rise of Mobile Professionals and Smartphone Adoption}

Kakihara, et al. [24] argued that technology developments and changing of organizational demand lead to the rise of mobile professionals, who are mobile and conduct their work activities at different locations because of extensive travel requirements intrinsic in job responsibilities. They constantly interact with diverse people in cooperation, both inside and outside the organization, in a large geographical area [25]. Activities of mobile professionals can be divided in three types i.e. travelling (mobility from one place to another), visiting (spending a long period at a fixed point) and wandering (local mobility in a small area) [9]; travelling is an essential part in mobile professional's work.

Smartphone technology assures mobile professionals that it can help them stay in touch with co-workers, customers, partners, and business processes, and keep them connected, responsive and efficient [26]. Therefore, the usage of smartphones during work is increasing. It is then strengthened with the 'Bring Your Own Device' (BYOD) discourse, which refers to the policy of permitting employees to personally bring their own mobile devices to their workplace as well as to use the device to access the company information and application [27]. 


\subsection{Scheduling, Coordination and Adjustment of Daily Activities}

During the recent decades, the decision-making process of activity scheduling and rescheduling has become an essential topic among transport researchers. Scheduling is the process of how people organize activities and travel, including their decision of what activities to do, where to do these, modes and routes used, where, when, how long and with whom [28]. During implementation, there is possibly rescheduling decisions, including modification/update with time, location, route, the people involved, event type, attributes of activities and trips, as well as deletions and additions of new events [14,29]. People make rescheduling decisions every day to revise and update their plans in order to resolve their daily activities and trips.

Often people coordinate themselves to arrange visits, manage schedules and synchronize activities everyday. Townsend [20] emphasized that the need to coordinate these activities is a basic social function, especially in contemporary society, which is characterized by distributed residential location, car-based transport, and complex activity patterns. It makes the impulsiveness of daily life increase. Sherry and Salvador [30] argued that another aspect of change found in mobile work is the emergence of a mixture of planning and improvisation of activities, which is similar to "rescheduling of activities" [15] and microcoordination [31]. Based on the literature review, the hypothesis of this paper is that a (1) Smartphone enables mobile professionals in the Greater Jakarta Area to dynamically plan, interact and execute his/her activity by adjusting his or her activity as the response to the information received; (2) By such adjustment, there are some implications on the travel characteristic of mobile professionals.

\section{$3 \quad$ Research Method}

The research objective is to observe the subsequent changes and probabilities of adjustment after mobile professionals receive the information from their Smartphone. This study examined the relationship between mobile interactions using smart phones, short term activity adaptation/activity (re)scheduling, and travel patterns of mobile professionals. The study consists of two phases, i.e. the preliminary and main study.

A preliminary survey was first conducted to get an initial insight into the phenomena. Considering that there is great diversity in the nature of mobile professionals' work and the characteristics of their technology use, it was important to recruit the interviewees: 20 mobile professionals from the Greater Jakarta Area, Indonesia. The domiciliary details of the respondents from the preliminary survey are as follows: in Jakarta (4), Bogor (3), Depok (4), Tangerang (4), and Bekasi (6). The range of occupations of the respondents 
include consultant (2), project manager/contractor (1), lawyer (1), journalist (2), veterinarian (1), obstetric-gynaecologic (1), CEO/owner (3), marketing (2), sales (2), customer service/account representation (1), property developer (1), programmer (1), lecturer-consultant (1) and government field-officer (1). Participants were also pre-screened to represent various levels of mobility in terms of flexibility of time, mobility and flexibility of work place. Semistructured interviews with open questions were conducted in this stage, with the aim of obtaining information on the context surrounding the mobile professionals' activities, for instance: why they make a trip, with whom they visit, what they will do with them, what they do with their mobile phone while travelling and at other locations, how they use their smartphones and especially for work purposes, what has changed in their mobile work as an implication of the use of smart phones, how they plan and make an activity-travel schedule, and how they execute the agenda (including how they reschedule the agenda). Time allocated for each interview in average is 30-45 minutes. All of the interviews were conducted in Indonesian. Interviews were transcribed and analyzed for the identification and sorting of themes and core concepts at several levels of specificity. Data obtained from the preliminary interview were then used as a basis to build a conceptual framework and create the next stage of the study, i.e. question items on the questionnaire as well as a scenario to capture stated adaptation in phase 2. The conceptual framework that resulted from the extraction of preliminary survey is shown on Figure 1. The travel impact of adjustment is given on Figure 2.

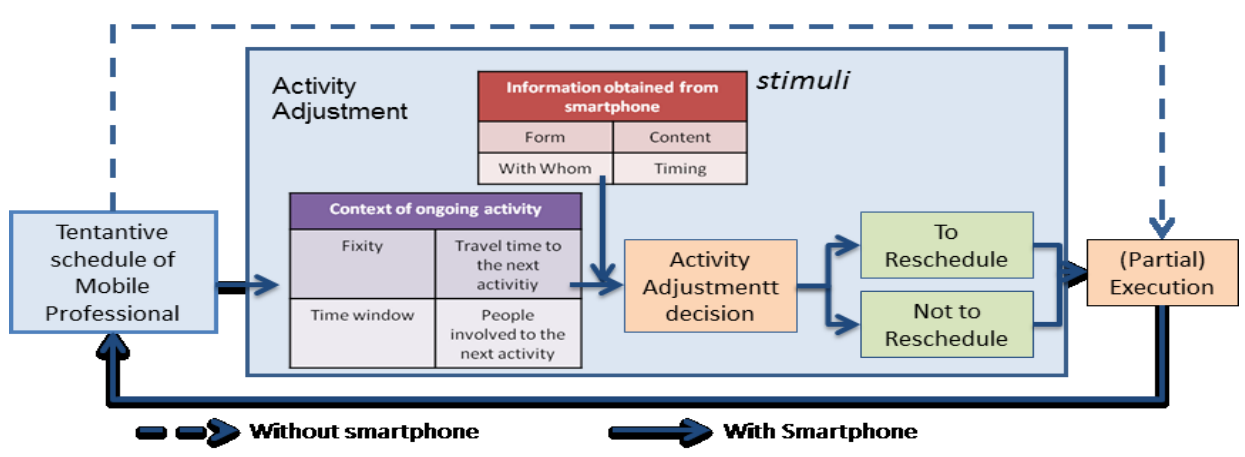

Figure 1 Conceptual framework of study.

Behavioural assumptions and mechanisms underlying the relationships shown by Figure 1 and Figure 2 are elaborated in the main survey. The main survey, which is the second phase of this study, is aimed to explore how a Smartphone enables mobile professionals in the Greater Jakarta Area to dynamically plan, interact and execute his/her tentative activity schedule by adjusting their activity in response to the information they have received. This phase was conducted by administering questionnaires to a much larger number of mobile professionals 
than that of the preliminary survey. Purposive and snowball sampling techniques were applied to 96 mobile professionals, with a combination of paper based F2F and online surveys (https://www.surveymonkey.com/s/ Mobile Prof 2014). 150 mobile professionals were actually contacted, via face to face interaction, phone calls, emails, social media (e.g. LinkedIn, Whatsapp), and then only 96 of them agreed to participate (Response rate is 64\%). The difficulty of making an appointment with mobile professional was the main reason why online surveys were offered. In this phase, there were 34 respondents who completed the online questionnaires (internet based survey/self-administered), while 62 respondents completed the paper based survey F2F. Respondents were recruited with the purposive technique combined with the snowball technique (this was a recommendation from prior respondents).

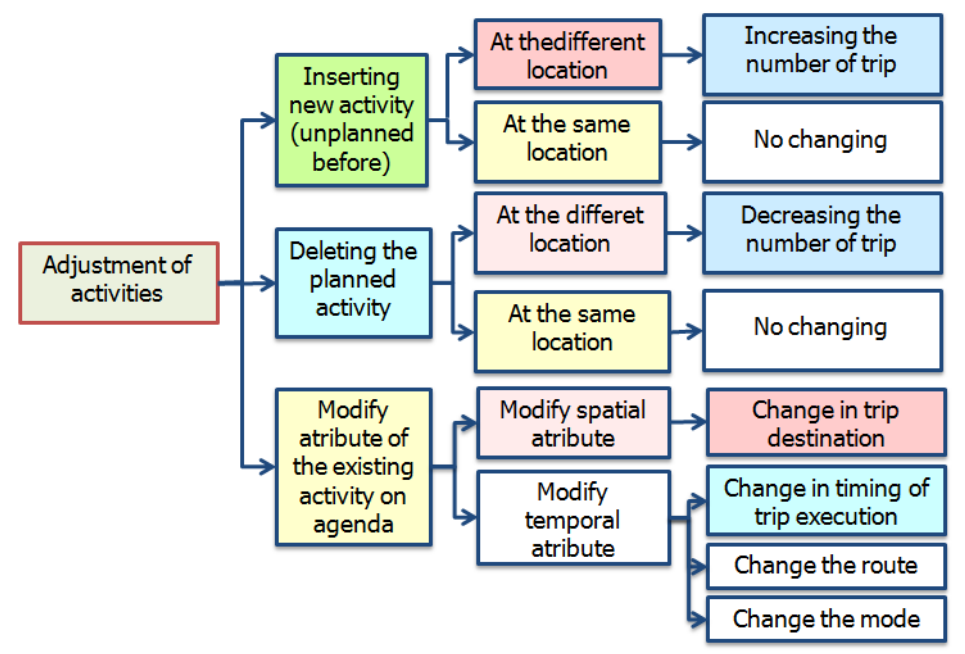

Figure 2 How adjustment of daily activities influences travel pattern.

Participants were asked to complete a socio-demographics profile and a one-day activity-travel diary (containing the execution, planned schedule, adjustments that they make, and why they make an adjustment/whether there is a relationship between their interactions via smartphone and the adjustment they make). Based on their travel diary, real experiences of the respondents regarding the adjustment could be captured. The respondents' daily travel distance, travel time and trip rate could be calculated from this data. Respondents were also confronted with a hypothetical situation in some scenarios, and then they were asked how they would respond to the situation during the execution of their activity-travel agenda. The purpose of this approach was to simplify the means of composing the basic patterns of activity adjustment that result from the interaction using smartphones. The scenario has 
been devised to be as real as possible, and in most cases it probably did occur. The selection of options provided must also be made as close to reality as possible. Within this context, the storyboard is built based on the experiences expressed by the mobile professionals on the preliminary survey. Based on the possible combinations, there should be $256 \times 36=9216$ scenario. Furthermore, the scenario is filtered into the scenario that is most likely to occur and which may lead to adjustment by using smart phone interactions based on what the respondents experienced in the previous phase. Through simplification 11 scenarios were obtained. In this approach, 11 scenarios/situations were generated on the storyboard as stimuli that contained "most probable information gained" from smart phone by using "what-if" questions, which requires immediate attention for adjusting decisions around "alternative realities" of the situation context.

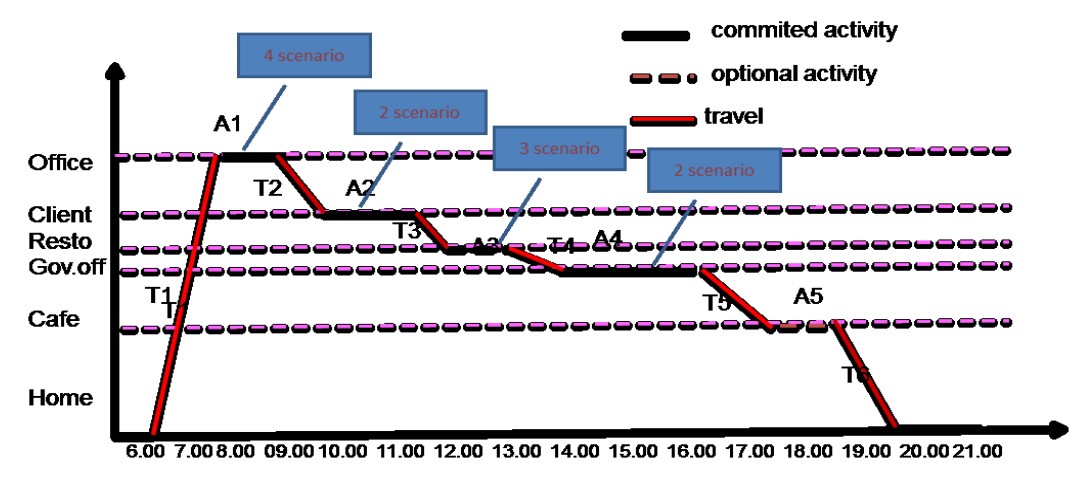

Figure 3 Time space graph of stated adaptation approach with 11 scenarios.

Simulation was divided into 4 timing episodes, i.e. morning (4 scenarios), before noon ( 2 scenarios), at lunch ( 3 scenarios) and afternoon ( 2 scenarios) as shown on Figure 3. Planned activities consisted of 3 committed activities and 2 optional activities, combined with the travel time to the location of activities, time window, and the people involved at that time and the next activity. Information obtained through smartphone is the combination of information forms, content of the information, with whom and when the interaction was performed. Adaptation options performed include insertion of new activities and removal of activities, insertion of new activities and activity modification, time modification, place modification, or even implementation of the planned activities. Choices were made as real as possible to the existing situations. 


\section{$4 \quad$ Result of Preliminary Survey and Discussion}

\subsection{Nature of Mobile Professional Work and Smartphone Adoption}

In general, all of respondents conducted more than one visit per day, and $42 \%$ of respondents even experienced more than four visits per day. The activities carried out by the mobile professionals in the office were internal management functions and administrative work, whereas activities outside office mainly consisted of attending meetings, servicing their customers, presenting their plans and explaining the progress of their work, and meeting with colleagues involved in the common platform project. Profiles of respondents are given in Table 1.

The respondents are tech savvy; they are proficient in the use of technology ( $82 \%$ of them have become users for more than 5 years); are very dependent on smartphone; $100 \%$ of them always have their smartphones turned on. Hence, we can say that they are always connected throughout the day, and use and take advantage of the facilities and services on it. Therefore, it is easier for mobile professionals to make contact and be contacted, and share real-time information in various forms. Interactions using smartphones allow them to coordinate and harmonize their activities. They are also connected with their family, friends and tend to respond to the information received from smartphone during work.

Table 1 Profile of Respondents; $\mathrm{n}=96$.

\begin{tabular}{|c|c|c|c|c|c|c|c|}
\hline Profile & $\%$ & Profile & $\%$ & Profile & $\%$ & Profile & $\%$ \\
\hline Gender & & Residence & & Level of Managerial & & \multicolumn{2}{|c|}{$\begin{array}{l}\text { Maximum location to } \\
\text { visit }\end{array}$} \\
\hline Male & $65 \%$ & Jakarta & $26 \%$ & Top & $33 \%$ & 2 places & $22 \%$ \\
\hline Female & $35 \%$ & Bogor & $13 \%$ & Midle & $67 \%$ & 3 places & $47 \%$ \\
\hline Age & & Depok & $17 \%$ & Expenditure/month & & $>3$ places & $31 \%$ \\
\hline $21-30$ & $6 \%$ & Tangerang & $10 \%$ & $<I D R 5$ million & $3 \%$ & \multicolumn{2}{|c|}{ Smart phone Ownership } \\
\hline $31-40$ & $40 \%$ & Bekasi & $34 \%$ & IDR 5-20 million & $51 \%$ & $1-5$ years & $18 \%$ \\
\hline $41-50$ & $43 \%$ & \multicolumn{2}{|c|}{ Location of mobile work } & $>I D R 20$ million & $46 \%$ & $>5$ years & $82 \%$ \\
\hline$>50$ & $11 \%$ & Jakarta & $100 \%$ & Mode to work & & \multicolumn{2}{|c|}{ Number of SIM card } \\
\hline Education & & Bogor & $60 \%$ & Motorcycle & $11 \%$ & Only 1 & $13 \%$ \\
\hline Bachelor & $56 \%$ & Depok & $22 \%$ & Car & $97 \%$ & $>1$ & $87 \%$ \\
\hline Master & $40 \%$ & Tangerang & $53 \%$ & Public transport (road) & $11 \%$ & \multicolumn{2}{|c|}{ Number of Smart phone } \\
\hline \multirow[t]{2}{*}{$P h D$} & $4 \%$ & Bekasi & $63 \%$ & Public transport (rail) & $8 \%$ & Only 1 & $21 \%$ \\
\hline & & & & & & $>1$ & $79 \%$ \\
\hline
\end{tabular}


During activity scheduling, smartphones are mostly used to make appointments, determine whether the meeting is important to do or not and to arrange a meeting. During execution, the main part of the interaction with smartphones from mobile professionals is to coordinate, collect work information and monitor the work of subordinates. Interactions using smartphones also provide respondents with opportunities to balance their responsibilities at work and family duties, as well as other interests. Before attending a meeting, smartphones are used to make confirmation and pre-travel verification. Around $80 \%$ of respondents use smartphones to gain information about traffic conditions and locations.

\subsection{Respondents' Experiences: Adjustment of the Daily Activity and its Influence on Travel Pattern}

From the preliminary survey, it was found that almost all respondents experienced adjustments of their daily activities. For instance, DHD, (account representative, 39) who said, "... Usually if there is an immediate change, I then use my smartphone to match the client's agenda and my activities. Activities and trips can be adjusted." RHD (CEO, owner, 49) revealed that, “...Appointments with business competitors and government officers, frequently change, either the venue or the time... at the last minute." Smartphone is a coordination tool that helps modify travel in the event of a change in activities and arrange adjustments. An adjustment was experienced by a respondent named RHS (ME engineer/ consultant, 41), who had a tentative schedule to visit 4 locations/5 trips (office-project- lunch meeting - client's office), with a travel length of 57 $\mathrm{km}$. During the day there were some interactions conducted via his smartphone with clients and colleagues, and using a traffic application he found out that there was a traffic jam on his next route. He made an adjustment four times: 2 additional trips, 1 modification of the activity start-time, and 1 route change. The total travel length, after adjustment, was $73 \mathrm{~km}$. In this case, RHS made an "inserting and modification" adjustment. In this situation, after the information is received, the respondents see the level of urgency, and then evaluate the information by looking at the agenda of the next event, consider the travel time and constraint, and then make a decision whether to change the schedule or not. Almost all respondents agreed that with a smartphone they are more productive and efficient.

From Phase 2, the real experience of respondents is found from the one day travel diary data. Although 96 respondents completed the questionnaires, only 52 travel diaries have been analysed and presented in this paper. One day activity-travel diaries of 52 respondents were used and the adjustments that they made have been classified, the composition can be seen in Figure 4. It was found that adjustments did not occur for only $8 \%$ respondents. This means that 
activity adjustments happened to most of the respondents. Inserting a new activity affects and increases the number of trips.

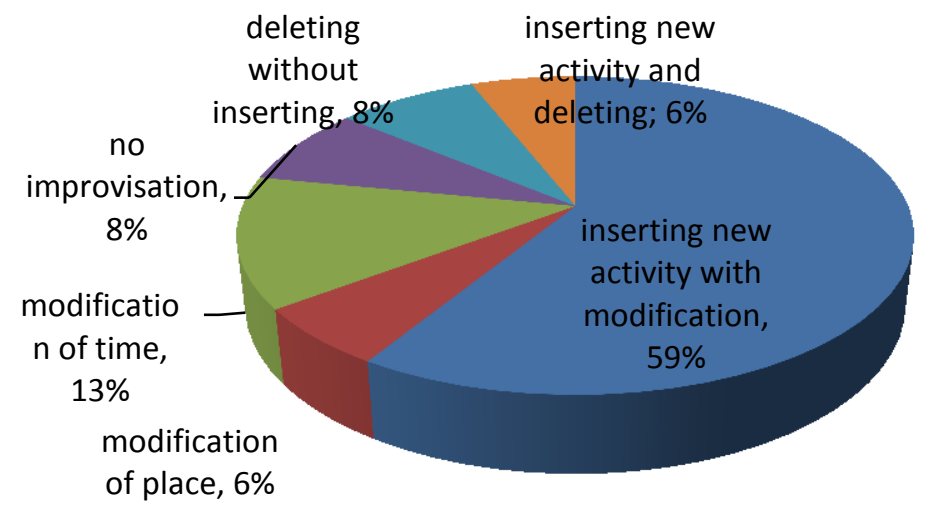

Figure 4 Adjustment Experience of one day travel diary of respondents.

Table 2 Travel Characteristic of Respondent using a one day activity-travel diary; comparisons between a tentative schedule and execution.

\begin{tabular}{|c|c|c|c|c|c|}
\hline \multicolumn{3}{|c|}{ Travel time (hour/day) } & \multicolumn{3}{|c|}{ Trip rate (trip/day) } \\
\hline \multirow{2}{*}{$\begin{array}{c}\text { Range } \\
\text { (hour/day) }\end{array}$} & Tentative & Execution & \multirow{2}{*}{$\begin{array}{c}\text { Trip } \\
\text { Number }\end{array}$} & \multirow{2}{*}{$\begin{array}{c}\text { Tentative } \\
\text { Frequency }\end{array}$} & \multirow{2}{*}{$\begin{array}{l}\text { Execution } \\
\text { Frequency }\end{array}$} \\
\hline & Frequency & Frequency & & & \\
\hline $1,50-2,25$ & 12 & 8 & 3 & 19 & 5 \\
\hline $2,50-3,25$ & 19 & 10 & 4 & 26 & 29 \\
\hline $3,50-4,25$ & 14 & 15 & 5 & 7 & 16 \\
\hline $4,50-5,25$ & 0 & 8 & 6 & 0 & 2 \\
\hline $5,50-6,25$ & 3 & 3 & & & \\
\hline $6,50-7,25$ & 4 & 8 & & & \\
\hline \multicolumn{6}{|c|}{ Travel Distance (Km/Day) } \\
\hline \multirow{2}{*}{$\begin{array}{c}\text { Range } \\
(\mathrm{km})\end{array}$} & Tentative & Execution & & \multicolumn{2}{|c|}{$\Delta$ Change $(\mathrm{Km})$} \\
\hline & Frequency & Frequency & & Range & Frequency \\
\hline $20-41$ & 11 & 8 & & $0-11$ & 28 \\
\hline $42-63$ & 23 & 10 & & $12-23$ & 13 \\
\hline $64-85$ & 11 & 16 & & $24-35$ & 1 \\
\hline $86-107$ & 0 & 7 & & $36-47$ & 3 \\
\hline $108-129$ & 7 & 6 & & $48-59$ & 3 \\
\hline $130-151$ & 0 & 5 & & $60-71$ & 4 \\
\hline
\end{tabular}


Still looking at the travel diary experienced by the 52 respondents, there are significant influences on travel characteristics when a tentative schedule and execution were compared. Table 2 shows how travel characteristic are influenced by the adjustment, due to smartphone usage during work. As it has been explained in the methodology, mobile professionals who do not use smartphones are assumed to execute the schedule as planned on their tentative schedule, without any adjustment.

Generally, Table 2 shows the distribution frequency shifting to the higher value on daily travel time, trip rate, and travel distance, in comparison with the tentative schedule and execution, this is due to the adjustment made during the implementation of the schedule as a response to the information received. The means of the daily trip rate, travel time and travel distance after adjustment are as shown, respectively: 4 trips/day; 4,29 hours/ day; and 79,25 km/day. However, it has been shown in Table 2 that the variability of the data is also high. This is probably due to the widespread living areas of the respondents (Jakarta, Bogor, Depok, Tangerang, and Bekasi), hence the variation of the travel distance is quite high, and Jakarta is the destination centre of mobile work from all respondents.

\subsection{Concept of Adjustment of Daily Activities Facilitated by Smartphone Adoption}

Furthermore, from the simulation results from the 96 respondents, a few things have been obtained about the basic rules of the adjustments that may occur when someone uses the information received during his-her work. After an individual makes a schedule for activities and movements, options may emerge during his-her activities, including from the information he/she receives through smartphones. Smartphones enable mobile professionals to gain more accurate and real time information, such as the condition of the people involved in the subsequent work activity (e.g. business partners, clients) or non-work activity (e.g. friend, family), or environment (e.g., weather, traffic), and reduce the uncertainty which influences their decision. This information plays an important role in determining their decision. Individuals process information and decide whether they revise or continue with the planned pattern beforehand, and this influences the order, attributes of space and time from the activities, the number of trips, timing, destination, length of trip, and travel time.

Using data from responses to the 11 scenarios, the tendency for all respondents to make an adjustment was found. The adaptation options performed by all respondents, for men and women, is compared and shown in Table 3. 
Table 3 Modus of Activity Adjustment Response, a Comparison between all Respondents, Men and Women.

\begin{tabular}{cccccccc}
\hline \multirow{2}{*}{ Scenario } & \multirow{2}{*}{$\begin{array}{c}\text { All } \\
\text { respondents }\end{array}$} & \multicolumn{2}{c}{ Male } & \multicolumn{2}{c}{ Female } & \multicolumn{2}{c}{ Differences in } \\
\cline { 3 - 8 } & Answer & \% & Answer & \% & Answer & \% \\
\hline 1 & a & a & 51,61 & a & 61,76 & - & 10,15 \\
2 & c & c & 61,29 & c & 55,88 & - & 5,41 \\
3 & d & d & 56,45 & d & 61,76 & - & 5,31 \\
4 & d & d & 53,23 & c & 50,00 & $\checkmark$ & \\
5 & b & b & 64,52 & b & 64,71 & - & 0,19 \\
6 & b & b & 70,97 & b & 82,35 & - & 11,39 \\
7 & b & b & 67,74 & b & 44,12 & - & 23,62 \\
8 & a & a & 66,13 & a & 47,06 & - & 19,07 \\
9 & a & a & 59,68 & b & 47,06 & $\checkmark$ & \\
10 & d & d & 40,32 & b & 79,41 & $\checkmark$ & \\
11 & c & c & 50,00 & b & 47,06 & $\checkmark$ & \\
\hline
\end{tabular}

Detailed scenarios and answers are not shown here but, in brief, it was found that the information obtained using smartphone provides a greater possibility to make adjustments to their daily activity. Table 3 shows that from 11 scenarios, 6 scenarios resulted in significantly different gender responses from the respondents, i.e. scenario no. $4,9,10$, and 11 . The gender of the respondents seems to play an important role in determining their options. Scenario no. 4: "In the morning, you are at the office, completing routine managerial matters, involving co-workers. Next event is a meeting with your customer $(A)$, in the costumer's office, which can take 30 minutes to drive from the current location and suddenly you receive information from your smart phone. What if your client (B) suddenly calls and tells you about some serious problems in the field, with a distance of 2 hours drive that needs immediate treatment. Your presence on the field is awaited. What might you do?" Male respondents choose to "Perform the planned activity with the client (A), and to only monitor the client's problems in the field (B) via smartphone", while female respondents tend to choose "delay planned activities with business partner $A$ to a different hour, but still on the same day, and then go to the location of business partner $B$ with urgency." In this case it seems that women are more concerned with the state of the emergency of the other client, and view it as something urgent and that they need to rearrange their schedule with client B as the priority, whereas men are calmer than women and not as reactive as women.

Furthermore, in scenario 11 (family-related information), female respondents have a strong modus in their response options. In scenario 11: "It is currently 
14:00. You're attending an important meeting with the government in the agency office. After this important meeting, you have a tentative activity; you will go home or hang out with your professional community in a cafe within 1 hour drive from the government office. What if a family member sends a message, asking you to do some errand such as to buy an object at a shopping centre located less than 30 minutes from the current location of your activity? Its picture is sent via smart phone.?" Men tend to choose "Approve the request of the family, leave for the shopping centre after the meeting and notify their friends in the cafe of their late arrival via smartphone", while women tend to choose "Approve request of the family, leave for the shopping centre after the meeting and cancel their plan to go to the cafe and then go home". When compared to men, women are more reactive and make immediate adjustments to their daily activities as soon as they get important information about their families. Valcour and Hunter [32] stated that women are more family-oriented and are more likely to intersperse their paid work with family related activities than men. The 4 scenarios that have significantly different reactions show that women and men have some different points of view or concern, and it influences the decision that they have make. Gender difference does not have any significant impacts on the decision in 5 scenarios, i.e. scenario number 1, 2, 3,5 , and 6 . However, both genders chose decision adaptations that change their original schedule.

Adaptations that the respondents reported indicates that the adjustments potentially arise with the increasing likelihood of someone receiving additional information that is relevant to his/her next activity, environmental conditions, travel, family, business partners, and co-workers. The information that they receive can be viewed as constraints that must be addressed, or as opportunities for new activities. Simulations with a larger sample size could be considered as a tool to propose a rule of response patterns that are due to the adoption of smartphones in various situations.

\section{Conclusion}

Preliminary findings from the study show that there are changes in the form of mobile professionals' adjustment of their daily activities, which is an implication of smartphone adoption. Smartphones fulfill the needs of users to support real time information in order to reduce the uncertainty associated with the contextual constraints they face while being mobile, and plays an important role in planning their activities before the trip, during the trip, and upon visiting, during the execution of activities. Mobile interactions using smartphones facilitate real time coordinations by giving an instant access to information. It enables mobile professionals to dynamically respond and adjust their activities after they receive information via smartphone. 
The main purpose of the adjustment is to cope with individual/work constraints of their daily activities. Although smartphone adoption affects the shifting of distribution frequency to the right (to the higher value), smartphone adoption also increases the daily trip rates, travel distance and travel time, but on the other hand, it can be seen as an effort to make the daily activity more productive (more activity can be implemented) and the daily trip more efficient by exploiting information obtained from their smartphone in order to diminish the uncertainty of the traffic condition, location and people involved. If transport planners could take into account the dynamics of travel patterns and the possibility of adjustments of daily activities through information received via smartphone on their planning, transport policy would be implemented well.

\section{References}

[1] Mokhtarian, P. \& Tal, G., Impact of ICT on Travel Behaviour: A Tapestry of Relationship, The Sage Handbook of Transport Studies, Rodrigue, J.P., Notteboom, T. \& Shaw, J., eds., Sage Publication, 2013.

[2] Google/IPSOS OTX Media CT, The Mobile Movement, Understanding Smartphone Users, U.S., 2011.

[3] ITU Telecom World, The World in 2013, ICT Fact and Figure, ICT Data and Statistics Division Telecommunication Development Bureau International Telecommunication Union, Switzerland, 2013.

[4] Charlesworth, A., The Ascent of the Smartphone, Engineering and Technology Magazine, 4(3), pp. 32-33, 2009.

[5] Nielsen, Smartphone Insight 2012, February, 2012.

[6] RIM, Blackberry Target Market, Overview, Research in Motion Limited, U.S., 2003.

[7] Ablondi, W. \& Elliot, T., Mobile Professional Market Segmentation Study, BIS, 1992.

[8] Frohlich, D., Requirements for Interpersonal Information Management, Personal Information Systems: Business Applications, Thomas, P.J., Ed., Stanley Thornes in Assoc. with Unicom Seminars, 1995.

[9] Kristoffersen, S. \& Ljungberg, F., Making Place to Make IT Work: Empirical Explorations of HCI for Mobile CSCW, GROUP'99: Proceedings of The International ACM SIGGROUP Conference on Supporting Group Work, Phoenix, AZ, New York: ACM Press, 1999.

[10] Crook, S.K., Jaffe, J., Boggs, R. \& Drake, S.D., Worldwide Mobile Worker Population 2011-2015 Forecast, IDC, 2011.

[11] Perry, M., O'Hara, K., Sellen, A., Harper, R. \& Brown, B.A.T., Dealing with Mobility: Understanding Access Anytime, Anywhere, ACM Transactions on Human-Computer Interaction, 8(4), 2001. 
[12] Mokhtarian, P.L., If Telecommunication is Such A Good Substitute for Travel, Why does Congestion Continue to Get Worse?, Transportation Letter, 1(1), pp. 1-17, 2009.

[13] Salomon, I., Telecommunications and Travel Relationships: A Review, Transportation Research, A20A(3), pp. 223-238, 1986.

[14] Joh, C.H., Measuring and Predicting Adaptation In Multidimensional Activity-Travel Patterns, $\mathrm{PhD}$ Dissertation Faculteit Bouwkunde, Capaciteitsgroep Stedebouw, Technische Universiteit Eindhoven, 2004.

[15] Axhausen, K. \& Gärling, T., Activity-Based Approaches to Travel Analysis: Conceptual Frameworks, Models, and Research Problems, Transp. Rev., 12(4), pp. 324-341, 1992.

[16] Suryo, Y., Facts on Smartphone Users in Indonesia, Canopy Asia, 2014

[17] Ericson, Ericson Mobility Report: on the Pulse of the Networked Society, http://www.ericsson.com/res/docs/2014/ericsson-mobility-reportfebruary-2014-interim.pdf,(30 May 2014)

[18] Miller, H.J., What About People in Geographic Information Science?, Re-Presenting Geographical Information Systems, Fisher, P. \& Unwin, D., eds., John Wiley, 2005.

[19] Kopomaa, T., The City in Your Pocket: Birth of the Mobile Information Society, Gaudeamus Kirja, Helsinki, Finland, 2000.

[20] Townsend, A., Life in the Real Time City: Mobile Telephones and the Urban Metabolism, Journal of Urban Technology, 7(2), pp. 85-104, 2002.

[21] Kwan, M.P., Mobile Communications, Social Networks, and Urban Travel: Hypertext as a New Metaphor for Conceptualizing Spatial Interaction, The Professional Geographer, 59(4), pp. 434-446, 2007.

[22] Hägerstrand, T., What About People in Regional Science?, Papers of the Regional Science Association, 24(1), pp. 6-21, 1970.

[23] Dijst, M., ICT and Social Networks: Toward a Situational Perspective on the Interaction Between Corporeal and Connected Presence, The Expanding Sphere of Travel Behaviour Research, Kitamura, R., Yoshii, T. \& Yamamoto, T., eds., International Association for Travel Behaviour Research, 2009.

[24] Kakihara, M., Sorensen, C. \& Wiberg, M., Fluid Interaction in Mobile Work Practices, Proceeding of $1^{\text {st }}$ Tokyo Mobile Roundtable, Mobile Innovation Research Program, Institute of Innovation Research Hitotsubashi, Tokyo, 2002.

[25] Jones, N., The Communicating, Connected, Real-Time Mobile Worker of 2015, Portals, Content \& Collaboration Summit, 2010.

[26] Research in Motion Limited, Mobile Unified Communications \& Collaboration (UCC).The CIO's Guide, http://nl.blackberry.com/content/ dam/blackBerry/pdf/cioGuide/CIO's_Guide_to_Mobile_UCC_brochure.p df, 2012 (16 April 2014). 
[27] Bradley, T., Pros and Cons of Bringing Your Own Device to Work, PCWorld, 20 December 2011, http://www.pcworld.com (16 June 2012).

[28] Doherty, S.T., Miller, E.J., Axhausen, K.W. \& Garling, T., A Conceptual Model of the Weekly Household Activity-Travel Scheduling Process, Travel Behaviour: Patterns, Implications and Modelling, Stern, E., Salomon, I. \& Bovy, P., eds., pp. 148-165, Cheltenham, UK: Elgar Publishing Ltd., 2008.

[29] Clark, A., The Human Activity-Travel Rescheduling Decision Process, Thesis of Master of Arts/Master of Environmental Studies Degree, Wilfrid Laurier University, 2008.

[30] Sherry, J. \& Salvador, T., Running and Grimacing: The Struggle for Balance in Mobile Work, Wireless World - Social and Interactional Aspects of the Mobile World, Brown, B., Green, N. \& Harper, R., eds., London, Springer-Verlag, pp. 108-120, 2002.

[31] Ling, R., The Mobile Connection (The Cell Phone's Impact on Society), Morgan Kaufman Publishers, Elsevier, 2004.

[32] Valcour, P.M. \& Hunter, L.W., Technology, Organizations, and WorkLife Integration, Work and Life Integration: Organizational, Cultural, and Individual Perspectives, Kossek, E.E. \& Lambert, S.J., eds., Mahwah, NJ: Erlbaum, pp. 61-84, 2005. 